\title{
Larva and pupa of Metaxycera purpurata (Chrysomelidae, Cassidinae, Chalepini)
}

\author{
Sônia A. Casari ${ }^{1,2}$ \\ 1. Museu de Zoologia, Universidade de São Paulo, Caixa Postal 42494, 04218-970 São Paulo, SP, Brasil. (casari@usp.br) \\ 2. CNPq fellowship.
}

\begin{abstract}
Larva and pupa of Metaxycera purpurata (Guérin-Méneville, 1844), collected on Cecropia (Cecropiaceae), are described and illustrated. They are the first immature forms described to this genus.
\end{abstract}

KEYWORDS. Cecropia, Chalepini, larva, Metaxycera, pupa.

RESUMO. Larva e pupa de Metaxycera purpurata (Chrysomelidae, Cassidinae, Chalepini). Larva e pupa de Metaxycera purpurata (Guérin-Méneville, 1844), coletados em Cecropia (Cecropiaceae), são descritos e ilustrados. São as primeiras formas imaturas descritas para esse gênero.

PALAVRAS-CHAVE. Cecropia, Chalepini, larva, Metaxycera, pupa.

The genus Metaxycera Baly, 1864 includes 12 species recorded from South America (STAINES, 2002). Up to now, the immatures of this genus were unknown. Herein, larva and pupa of $M$. purpurata (GuérinMéneville, 1844) are described and illustrated.

Immatures of Metaxycera purpurata (GuérinMéneville, 1844) were collected on Cecropia (Cecropiaceae). This host-plant had been cited by Jolivet \& Hawkeswood (1995) apud Staines (2002).

\section{Metaxycera purpurata (Guérin-Méneville, 1844) (Figs. 1-23)}

Larva. Length: 5.5-9.5 mm (young larvae); 11.5$12.5 \mathrm{~mm}$ (mature larvae). Elongate, wide and flattened (Figs. 1, 2). Integument (Figs. 17-22) slightly sclerotized, with microgranulose appearance, clothed with microspines (visible only under high magnification) (Figs. 20, 22), pale except head, legs and spiracular openings, brown; pronotum and prosternum with wide sclerotized plate. Head (Figs. 3, 4) prognathous, narrower than prothorax; epicranial stem absent; frontal arms V-shaped; median endocarina well developed, extending between frontal arms. Five stemmata on each side: 2 lateral, 2 ventral and 1 dorsal. Each side of frons bearing 7 setae except 3 of clypeal area. Each epicranial plate bearing 11 dorsal setae. Frontoclipeal suture indistinct. Clypeal area with 3 pairs of short setae. Labrum (Fig. 9) transverse, band-like, irregularly notched medioanteriorly, each side with 2 microsetae near base. Epipharynx (Fig. 10): anteriorly each side with 5 very wide setae disposed in a row and several narrower setae disposed in a tuft-like, innerly to each row; one well developed sclerite at middle; each side with an area with microtrichiae and 2 sensorial pores and 1 microseta innerly; microsetae surrounding median sclerite, more concentrate near base; 2 pores at base, below median sclerite. Antennae (Figs. 7, 8) with 3 antennomeres: basal almost as long as wide; median, slightly narrower than anterior, longer than wide, bearing at apex, a cupuliform, well developed membranous sensorium laterointernally and distal antennomere lateroexternally, and near apex, 1 seta dorsal and 1 ventral and 1 small sensorium at base of distal sensorium; antennomere distal shorter, bearing at apex, 4 long setae and one membranous sensorium at middle. Gula absent. Mandibles (Figs. 5,6) robust with one dorsal pore and 2 laterobasal short setae. Maxillolabial complex (Figs. 11, 18) almost as long as head ventrally. Maxilla elongate, cardo indistinguishable; mala (Figs. 11-13) elongate, ventrally with 4 very wide distal setae and 3 very short laterointernally near middle, and dorsally, densely clothed with short setae; maxillary palpi with 2 palpomeres; palpomere basal bearing 1 lateroexternal seta; distal palpomere smaller with 1 laterointernal long seta and several stout short setae at apex; stipes very long, bearing 3 short setae anteriorly and 5 lateroexternally near base. Labium elongate; palpi with 2 palpomeres; palpomere basal robust with 2 microsetae, distal smaller with short setae at apex; ligula well developed, rounded and fringed with short setae; prementum with 2 microsetae each side, above palpi; postmentum elongate with 7 short setae. Pronotum transverse, longer than meso- or metanotum; meso- and metanotum band-like. Legs (Figs. 2, 14, 18, 22) well separated, 4-segmented; coxa narrow, band-like with 3 short setae; femur and trochanter fused, wider than long, bearing 9 setae; tibia with 9 setae, more concentrated on distal third; tarsungulus without setae. Annular spiracles ventrolateral anterior on mesothorax (Fig. 22) and dorsolateral on segments 1-8. Abdominal segments 1-7 band-like with lateral lobes and ampullae dorsal (Fig. 19) and ventral (Fig. 21), more developed dorsally; segment 8 longer, narrowed toward apex, 

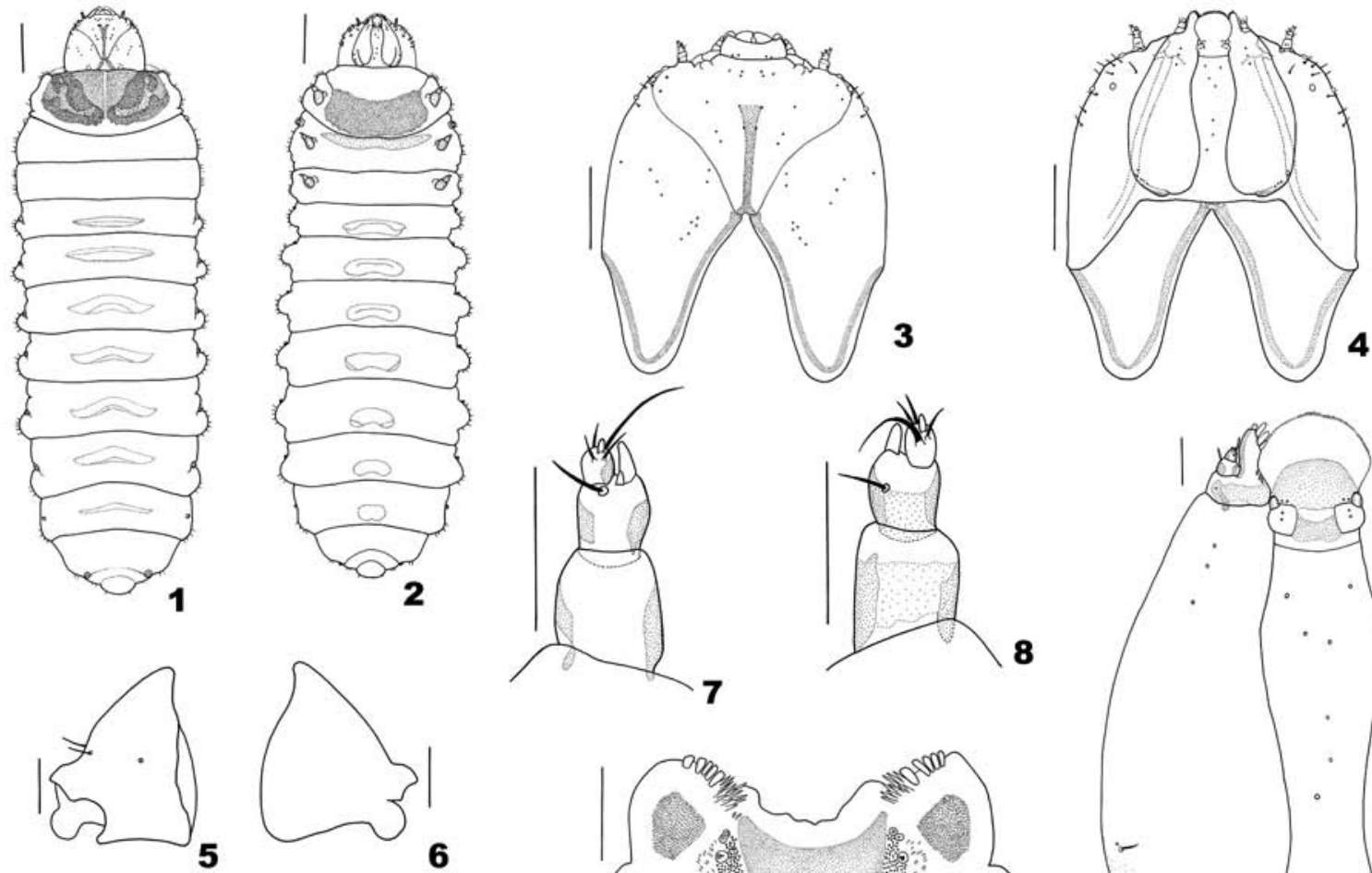

6

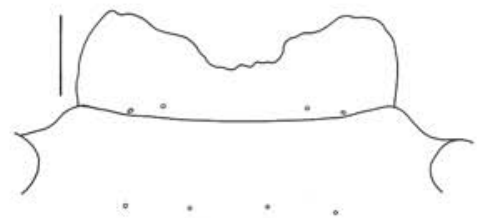

9

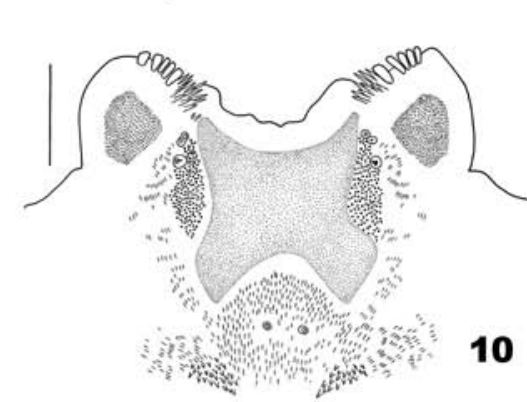

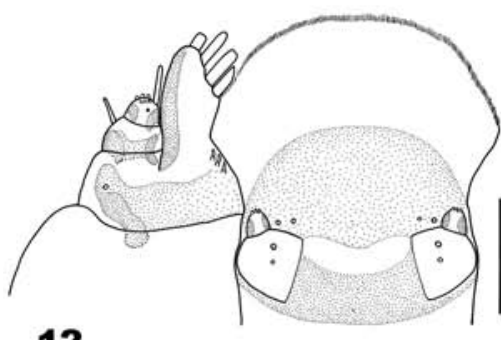

12

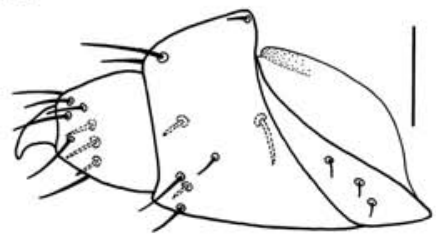

14
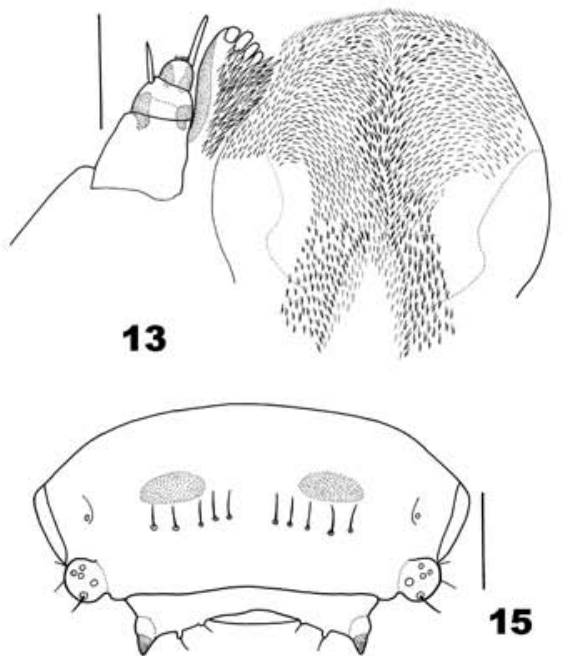

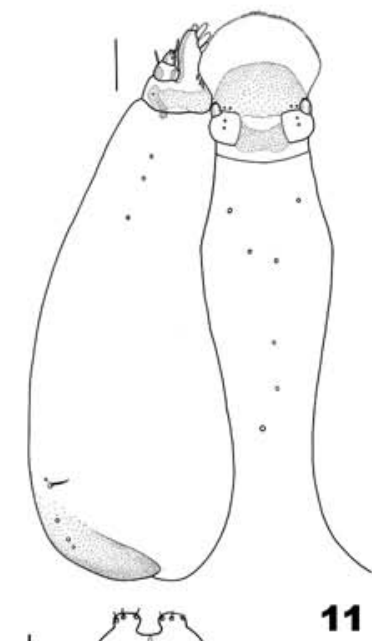

10
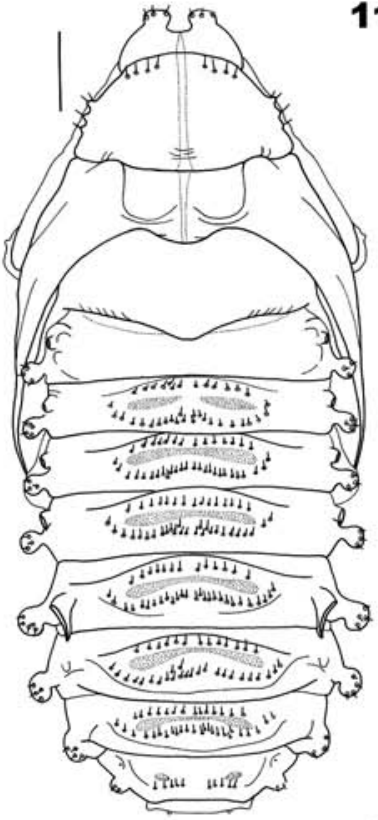

16

Figs. 1-16. Metaxycera purpurata (Guérin-Méneville, 1844). Larva: 1, 2, habitus (dorsal, ventral); 3, 4, head (dorsal, ventral); 5, 6, mandible (dorsal, ventral); 7, 8, antenna (ventral, dorsal); 9, labrum; 10, epipharynx; 11, maxilla and labium; 12, 13, apex of maxilla and labium (ventral, dorsal); 14, leg. Pupa: 15, apex of abdomen (dorsal); 16, habitus (dorsal). Bars, $1 \mathrm{~mm}$; except Figs. 3, 4, 5 mm and Fig. 15, $0.5 \mathrm{~mm}$.

with dorsolateral spiracles near apex; segment 9 very short, band-like; segment 10 reduced and distal; anal opening distal.
Pupa (Figs. 15, 16). Length: 10-12 mm. Flattened; color brownish. Head partially visible from above, with 2 well developed rounded tubercles bearing short 


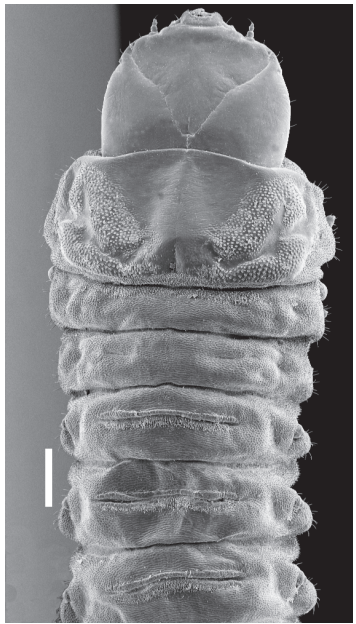

17

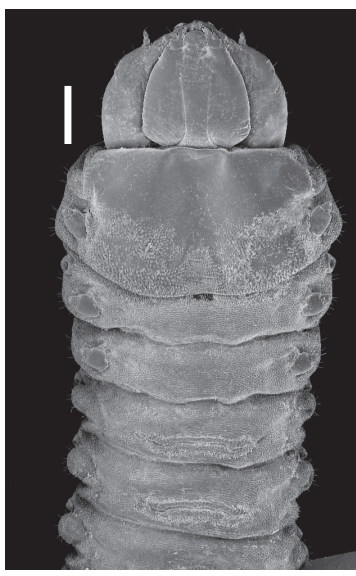

18

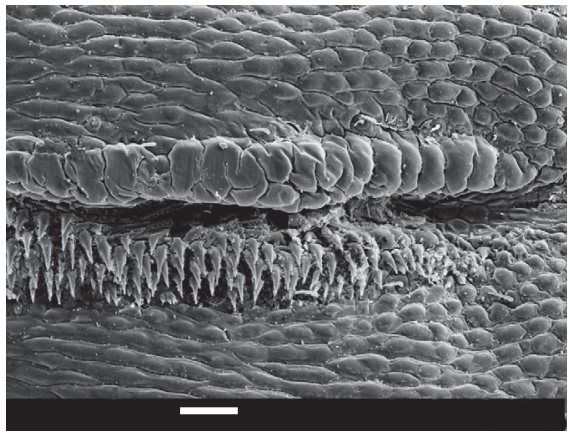

19

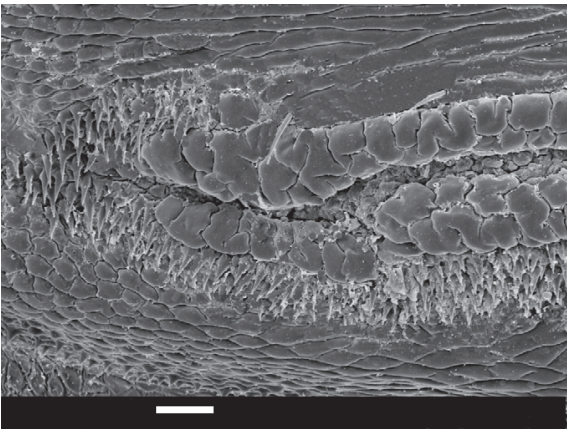

21

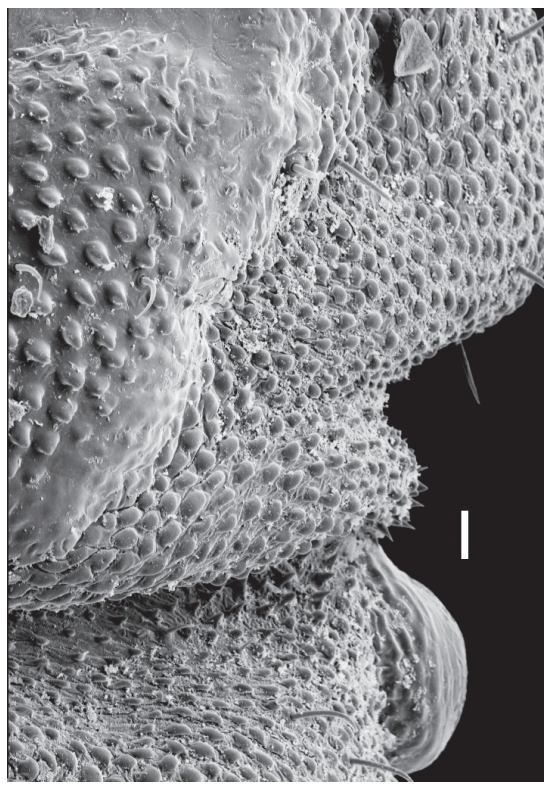

20

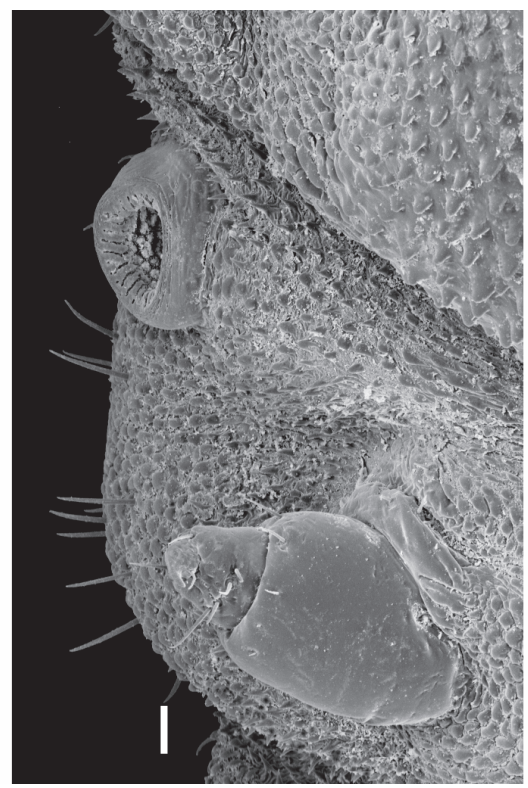

22

Figs. 17-22. Metaxycera purpurata (Guérin-Méneville, 1844). Larva: 17, 18, head, thorax and 3 first abdominal segments (dorsal, ventral); 19, 21, 1st abdominal ampulla (dorsal, ventral); 20, detail of integument of pro- and mesothorax (dorsolateral); 22, detail

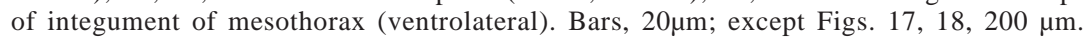

setae. Pronotum subtrapezoidal with setae near anterior margin; posterior margin sinuous; each lateral margin bearing 3 small tubercles with seta. Abdominal segments 1-8, each with 1 pair of lateral rounded projections with short setae near apex; segments 1-4 each with 1 pair of dorsolateral tubular projections of spiracular openings; segment 5 with 1 pair of dorsolateral sclerotized horn-like projections of spiracular openings; segment 9 (Fig. 15) band-like with 1 sclerotized well developed projection at each posterior angle. Tergites 2-7 with elliptical transverse row of stout setae with an sclerite at middle (interrupted on tergite 2); tergites 8 with a row of fine setae and 2 small sclerites.

Material examined. BRAZIL, São Paulo: Campinas, XI.1995, A. L. Lourenção col., 25 young larvae, 4 mature larvae, 7 pupae, 5 adults. All material housed at Museu de Zoologia, Universidade de São Paulo (MZ-9002).

Remarks. Immatures of Chalepini are little known. CAsari \& TeIXeIra (2004) described the larvae of Heterispa vinula (Erichson, 1847) and Physocoryna

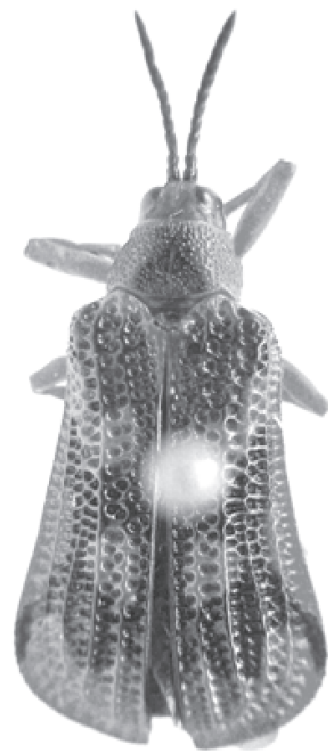

Fig. 23. Metaxycera purpurata (Guérin-Méneville, 1844): habitus (dorsal); lenght, $9.1 \mathrm{~mm}$. 
scabra Guérin-Méneville,1844. Comparing the larva of Metaxycera purpurata with the other known Chalepini, it was verified that: 1) Heterispa presents the lateral projections on abdominal segments and 6 stemmata on each side, and Metaxycera and Physocorina, lateral rounded lobes at abdominal segments and 5 stemmata; 2) all larvae, except that of Metaxycera present a transversal row of microspines or microtrichiae (ampullae) on meso-, metanotum and abdominal segments 1-8 or 1-7; Metaxycera presents ampullae only on abdominal segments; 3 ) frontoclipeal suture incomplete or indistinct in all known larvae; 4) all known larvae present legs 4-segmented, in Heterispa and Physocoryna, tibiae with, respectively, one and two lobes at apex; 5) mandibles 5-toothed in Physocoryna, 3 -toothed in Heterispa and only with apical tooth in Metaxycera; 6) labial palp with one palpomere, except
Metaxycera with two.

Comparing the pupa of Metaxycera purpurata with Heterispa vinula, it was observed that the former presents, on abdominal segments, lateral rounded projections and dorsal transverse rows of microsetae and sclerites, while the latter presents the lateral projections and the abdominal setae very long. Both have spiracular openings of segment 5 horn-like.

\section{REFERENCES}

Casari, S. A. \& Teixeira, E. P. 2004. Immatures of Heterispa vinula (Erichson) and Physocoryna scabra Guérin-Méneville (Coleoptera, Chrysomelidae, Cassidinae, Chalepini). Revista Brasileira de Entomologia 48(4):473-480.

Staines, C. L. 2002. The New World tribes and genera of Hispines (Coleoptera: Chrysomelidae: Cassidinae). Proceedings of the Entomological Society of Washington 104(3):721784. 